\title{
A Proprioceptive Role for an Exteroceptive Mechanoafferent Neuron in Aplysia
}

\author{
Dmitry Borovikov, ${ }^{1}$ Colin G. Evans, ${ }^{1}$ Jian Jing, ${ }^{1}$ Steven C. Rosen, ${ }^{3}$ and Elizabeth C. Cropper ${ }^{1,2}$ \\ ${ }^{1}$ Department of Physiology and Biophysics and ${ }^{2}$ the Fishberg Center for Research in Neurobiology, The Mount Sinai \\ Medical Center, New York, New York 10029, and ${ }^{3}$ Center for Neurobiology and Behavior, New York State Psychiatric \\ Institute and College of Physicians and Surgeons of Columbia University, New York, New York 10032
}

\begin{abstract}
Afferent regulation of centrally generated activity is likely to be more complex than has been established. We show that a neuron that is an exteroceptor can also function as a proprioceptor. We study the Aplysia neuron B21. Previous data suggest that B21 functions as an exteroceptor during the radula closing/retraction phase of ingestive feeding. We show that the tissue innervated by B21, the subradula tissue (SRT), is innervated by a motor neuron (B66) and that B66-induced SRT contractions trigger centripetal spikes in B21. Thus, B21 is also a proprioceptor. To determine whether exteroceptive and proprioceptive activities occur during the same phase of ingestive feeding, we further characterize B66. We show that B66 stimulation does not close or retract the radula. Instead it opens it. Moreover, B66 is electrically coupled to other opening/protraction neurons. Finally, we elicit motor programs in semi-intact preparations and show that during radula opening/protraction we observe B66 activity, SRT contractions, and spikes in B21
\end{abstract}

that can be eliminated if B66 is indirectly hyperpolarized. B21 is, therefore, likely to act as an exteroceptor during one phase of ingestive feeding and as a proprioceptor during the antagonistic phase. Previous experiments have shown that centripetal spikes in B21 are only transmitted to one follower if they are "gated in" by depolarization. During ingestive programs B21 is centrally depolarized during closing/retraction, but it is not depolarized during opening/protraction. We sought to determine whether there are other followers that receive B21 input when it is not centrally depolarized. We found one such cell. Moreover, we found that stimulation of B21 during radula opening/protraction significantly decreases the duration of this phase of behavior. Thus, proprioceptive activity in B21 is likely to have an impact on motor programs.

Key words: sensorimotor integration; sensory gating; central pattern generator; multisensory; multimodal sensory neuron; motor program
Rhythmic behaviors often result from the activity of central pattern generators (CPGs). Although CPGs are active in isolated preparations (Delcomyn, 1980) in many cases parametric features of these motor programs are not identical to those observed under physiological conditions. Under normal circumstances CPGs receive input from peripheral receptors [for review, see Pearson and Ramirez (1997); Rossignol et al. (1998); molluscan references include Kater and Rowell (1973); Siegler (1977); Reingold and Gelperin (1980); Jahan-Parwar et al. (1983)]. Much progress has been made in studies that have determined how sensory input is integrated into centrally generated motor programs. It has been pointed out, however, that afferent regulation of CPG function is likely to be more complex than has been established (Pearson and Ramirez, 1997). Current experiments generally study afferents activated by a single type of stimulus in a relatively controlled manner. Under physiological conditions, however, afferent activity is likely to be more complex. We show

Received Nov. 16, 1999; accepted Dec. 13, 1999.

This work was supported by an Irma T. Hirschl Career Scientist Award, K02 Award MH01267, K05 Award MH01591, and Public Health Service Grants MH51393 and MH35564. Some of the Aplysia used in this study were provided by the National Resource for Aplysia of the University of Miami under the National Center for Research Resources, National Institutes of Health, Grant RR10294. We thank R. A. DiCaprio, K. R. Weiss, and I. Kupfermann for valuable comments on a previous version of this manuscript.

Correspondence should be addressed to Dr. E. C. Cropper, Department of Physiology and Biophysics, Box 1218, Mount Sinai Medical School, 1 Gustave L. Levy Place, New York, NY 10029. E-mail: croppe01@doc.mssm.edu.

Dr. Evans's present address: Phase V Communications Inc., 114 Fifth Avenue, New York, NY 10011.

Copyright (C) 2000 Society for Neuroscience $\quad 0270-6474 / 00 / 201990-13 \$ 15.00 / 0$ that a mechanoreceptor that is an exteroceptor can also function as a proprioceptor.

Specifically, we study a cell, B21, that is an identified (Rosen et al., 2000b) member of a cluster of similar neurons that have a relatively low threshold for tactile stimuli. These cells are exteroceptors in that they are activated when an object touches the biting surface of the food-grasping organ in Aplysia, the radula (Miller et al., 1994; Rosen et al., 2000b). [Similar mechanoafferents have been described in other molluscs (Kawahara et al., 1994, 1995).] Exteroceptive activity in mechanoafferents like B21 is likely to be important for changes in ingestive motor programs that are necessary for food ingestion. Specifically, when Aplysia feed, the radula opens and protracts and then closes and retracts. When food is not ingested, retraction occurs until the buccal mass returns to a neutral position. In contrast, when food is ingested, the radula moves beyond the neutral position so that food is deposited in the esophagus (Weiss et al., 1986; Drushel et al., 1997; Evans and Cropper, 1998). Consequently, the radula closing/retraction phase of behavior is prolonged and enhanced (Cropper et al., 1990). Data indicate that radula mechanoafferents like B21 are likely to be important in this context because they will be activated when the radula closes on food and they make extensive excitatory connections with buccal interneurons and motor neurons.

In this study we demonstrate that the tissue innervated by B21, the subradula tissue (SRT), is innervated by a motor neuron. Therefore, B21 is actually a dual function sensory neuron; i.e., it is activated by proprioceptive and exteroceptive stimuli. Data 
suggest that B21 acts as an exteroceptor during the closing/ retraction phase of ingestive motor programs (Rosen et al., 2000a,b). In contrast, we show that B21 acts as a proprioceptor during the antagonistic phase of behavior-radula opening/protraction. Thus, B21 is active during both radula opening/protraction and radula closing/retraction but presumably functions as a proprioceptor during opening/protraction and as an exteroceptor during closing/retraction. Previous studies have suggested that when B21 functions as an exteroceptor centripetal activity is transmitted to all characterized follower neurons (Rosen et al., 2000a,b). In contrast, we show that when B21 functions as a proprioceptor centripetal activity is not transmitted to all of B21's postsynaptic targets. Thus, our data suggest that there can be flexibility in afferent feedback in that a dual function sensory neuron can transmit one type of information to all of its followers whereas only a subset of its follower neurons receives another type of information.

Parts of this paper have been published previously (Borovikov et al., 1997).

\section{MATERIALS AND METHODS}

Experiments were conducted in Aplysia californica (200-250 gm; Marinus, Long Beach, CA) that had been maintained in $14-16^{\circ} \mathrm{C}$ holding tanks. Animals were anesthetized with isotonic $\mathrm{MgCl}_{2}$ and then dissected to create reduced preparations. The nomenclature follows that of Gardner (1971).

Experiments were conducted in three types of preparations. The first type of preparation simply consisted of the isolated buccal and cerebral ganglia. This type of preparation was used in experiments in which single cycles of ingestive motor programs were elicited by stimulation of the command-like neuron cerebral buccal interneuron 2 (CBI-2) (Rosen et al., 1991; Church and Lloyd, 1994).

In the second type of preparation the buccal mass, radula nerve, and buccal nerves 1,2 , and 3 were left intact. To observe radula movements we made a small "window" on the dorsal surface of the buccal mass. Preparations were transferred to Sylgard-lined dishes, and the cerebral ganglion was generally pharmacologically isolated from the buccal ganglion and buccal mass. This isolation was accomplished when a subchamber was placed over the cerebral ganglion. This preparation was used to observe radula movements that occurred as a result of direct stimulation of motor neurons or to observe radula movements that occurred during multicycle motor programs. Motor programs were elicited by application of carbachol $\left(10^{-3} \mathrm{M}\right)$ to the cerebral ganglion (Susswein et al., 1996) or by stimulation of CBI-2.

The third type of preparation was similar to one that has been described (Cropper et al., 1996). In some experiments the SRT was removed from the chitinous radula and cut in half. In other experiments the radula sac was removed, but the SRT was left attached to the radula. The radula nerve, buccal nerve 3, buccal ganglion, and sometimes the cerebral ganglion were left intact. The SRT was attached to an isotonic force transducer (Harvard Apparatus), as has been described (Cropper et al., 1996). Briefly, the SRT was not directly attached to the transducer. Instead it was attached to a lever (i.e., a wooden stick) that made contact with the transducer and was, therefore, immobilized and served as a pivot point. To attach the SRT to the lever, one end of a piece of string was tied to the SRT. The other end of the string had a loop that was hooked over a metal hook on one end of the lever. This preparation was used in experiments in which SRT contractions were monitored and in some experiments in which B21 was centripetally activated. When B21 was centripetally activated in this type of preparation we attached the free end of the lever to an electromagnet, which was activated by a Grass stimulator to produce a stretch of $\sim 0.5 \mathrm{~mm}$.

Intracellular techniques were used to record membrane potentials and inject current. Neurons were impaled with single-barreled glass microelectrodes that were filled with $2 \mathrm{M}$ potassium acetate and beveled to impedances of 5-8 M $\Omega$. Muscle fibers and processes of B21 were impaled with microelectrodes with impedances of $35-40 \mathrm{M} \Omega$.

To visualize neurons, a 3\% solution of the fluorescent dye 5(6)carboxyfluorescein (Rao et al., 1986) was iontophoresed into cells from single-barreled glass microelectrodes with tips beveled to lower impedances to $10 \mathrm{M} \Omega$. To reduce active transport of the dye, probenecid (10

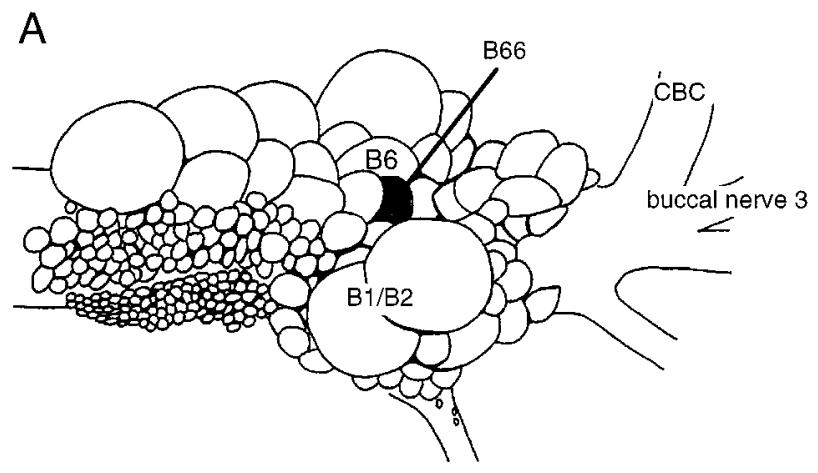

B

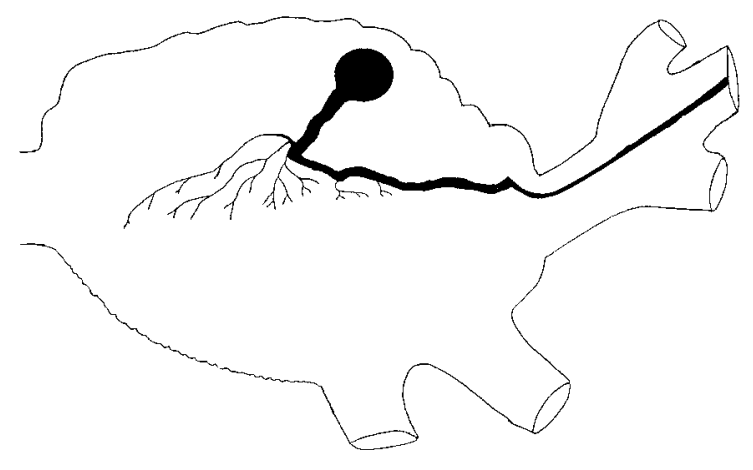

Figure 1. Morphology of B66. A, Schematic drawing of the caudal surface of the desheathed buccal ganglion. The position of the filled cell indicates the position of B66. Neurons B1/2 and B6 are labeled as reference cells. The drawing is after Hurwitz et al. (1997). $C B C$, Cerebral-buccal connective. $B$, Drawing of B66 injected with carboxyfluorescein dye. Note that B66 has an axon in buccal nerve 3.

mM final concentration) was added to preparations (Steinberg et al., 1987; Rosen et al., 1991), which were kept at $4^{\circ} \mathrm{C}$ for $24 \mathrm{hr}$.

In experiments in which B21's lateral process was lesioned we used two techniques. In some cases we used a micro blade (Becton Dickinson; supplied by George Tiemann, Hauppauge, NY) positioned with a micromanipulator. In other cases we used a handheld glass pipette. In some experiments B21 neurons were filled with carboxyfluorescein to demonstrate that lesions had in fact occurred. In other experiments B21 was filled with fast green dye, and the lateral process was directly visualized, as it was lesioned. In the latter experiments B8 was injected with carboxyfluorescein, and its processes were visualized to insure that the B21 lesion had not damaged them.

\section{RESULTS}

\section{Characterization of an SRT motor neuron}

We found a motor neuron that could elicit contractions of the SRT on the caudal surface of the buccal ganglion. This neuron (which we designated B66) was located near B6 (Fig. 1 $A$ ) and had an axon in buccal nerve 3 (Fig. $1 B ; n=4$ ). B66 had a mean resting membrane potential of $-60 \mathrm{mV}$ (range from -50 to -72 $\mathrm{mV} ; n=9)$. Intracellular recordings from SRT muscle fibers showed that spikes in B66 elicited one-for-one excitatory junction potentials (EJPs) that persisted when the buccal ganglion was placed in high-divalent isotonic artificial seawater (ASW) (Fig. $2 A$ ). B66-elicited EJPs were $\sim 2-2.5 \mathrm{mV}$ in amplitude and were recorded with a latency of $\sim 100 \mathrm{msec}(n=6)$. Single EJPs elicited by stimulation of B66 did not produce noticeable muscle contractions. However, if B66 was stimulated in bursts, with an intraburst firing frequency of from 3 to $4 \mathrm{~Hz}$, muscle contractions were triggered (Fig. $2 B ; n=10$ ).

To determine whether B66 is likely to be cholinergic, we 


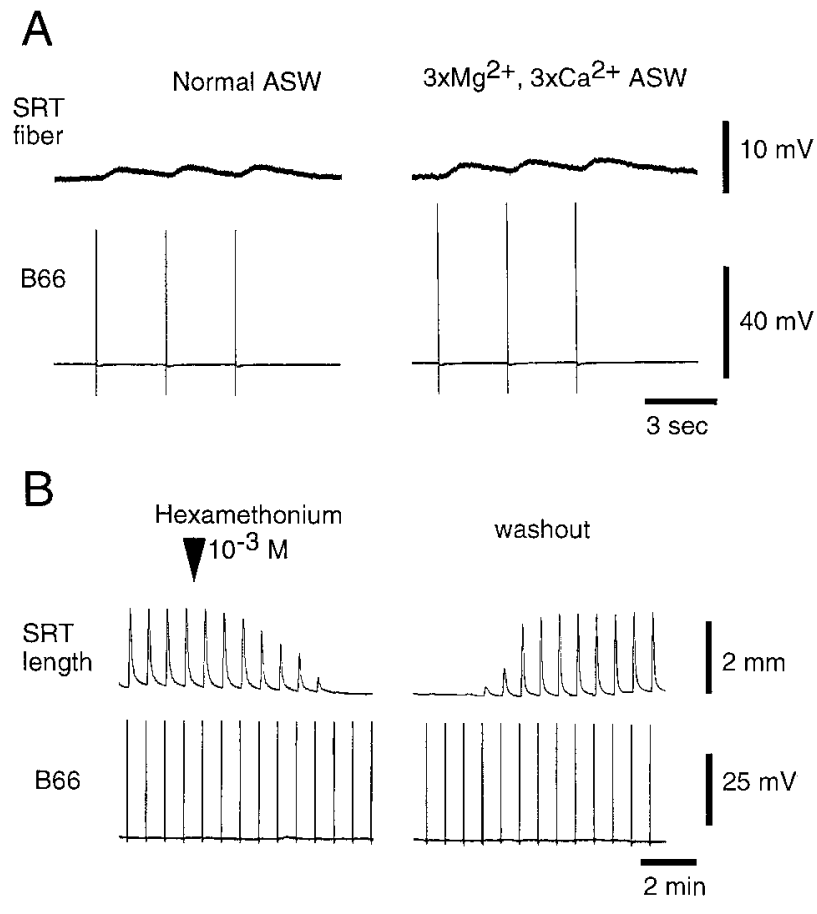

Figure 2. The B66 and SRT neuromuscular junction. A, Left, Excitatory junctional potentials recorded intracellularly from SRT fibers (top) induced by intracellular stimulation of B66 (bottom) in normal ASW. Right, Same experiment with the buccal ganglion bathed in a $3 \times \mathrm{Mg}^{+2}$ and $3 \times$ $\mathrm{Ca}^{+2}$ solution. $B$, Inhibition of SRT contractions by hexamethonium. SRT contractions were measured with an isotonic force transducer (top) and elicited by intracellular stimulation of B66 (bottom). Left, Application of hexamethonium. Right, Washout with ASW.

perfused the SRT with hexamethonium $(n=6)$. When hexamethonium was added at a concentration of $10^{-4} \mathrm{M}$, muscle contractions elicited by neuronal stimulation were reduced in size (data not shown). When the concentration of hexamethonium was increased to $10^{-3} \mathrm{M}$, contractions were completely and reversibly abolished (Fig. 2B).

We found strong bidirectional electrical connections between B66 and three cells that are active during the radula opening/ protraction phase of ingestive motor programs [i.e., B61/62 (Hurwitz et al., 1994, 1996), B48 (Church and Lloyd, 1994; Evans et al., 1996), and B13 (Gardner, 1977; Church and Lloyd, 1994)]. We found the strongest electrical coupling between B66 and B61/62 (Fig. 3) and between B66 and B48 (Fig. 4) (coupling ratios, $0.25-0.35 ; n=6$ and 8 , respectively). We also found electrical coupling between B66 and B13 (Fig. 5). In this case however the coupling ratio was less $(0.1-0.15$ from B13 to B66 and 0.05-0.08 from $\mathrm{B} 66$ to $\mathrm{B} 13 ; n=4)$. The directionality of this connection may be caused by the difference in size between these two neurons (B13 is approximately twice as big as B66). Thus we have found that the newly identified motor neuron B66 is electrically coupled to neurons active during the radula opening/protraction phase of ingestive motor programs.

\section{Stimulation of $\mathbf{B} 66$ produces radula opening}

To determine whether activity in B66 and the resulting contraction of the SRT could produce a radula movement that could be important for feeding, we used a semi-intact buccal mass preparation. When $\mathrm{B} 66$ was stimulated we observed that the ipsilateral radula half moved away from the buccal mass midline; i.e., the radula opened (Fig. 6; $n=10$ ). Because B66 is not the first motor

\section{A Normal ASW $\quad 0.5 \times \mathrm{Ca}^{2+}, 2 \times \mathrm{Mg}^{2+} \mathrm{ASW}$}
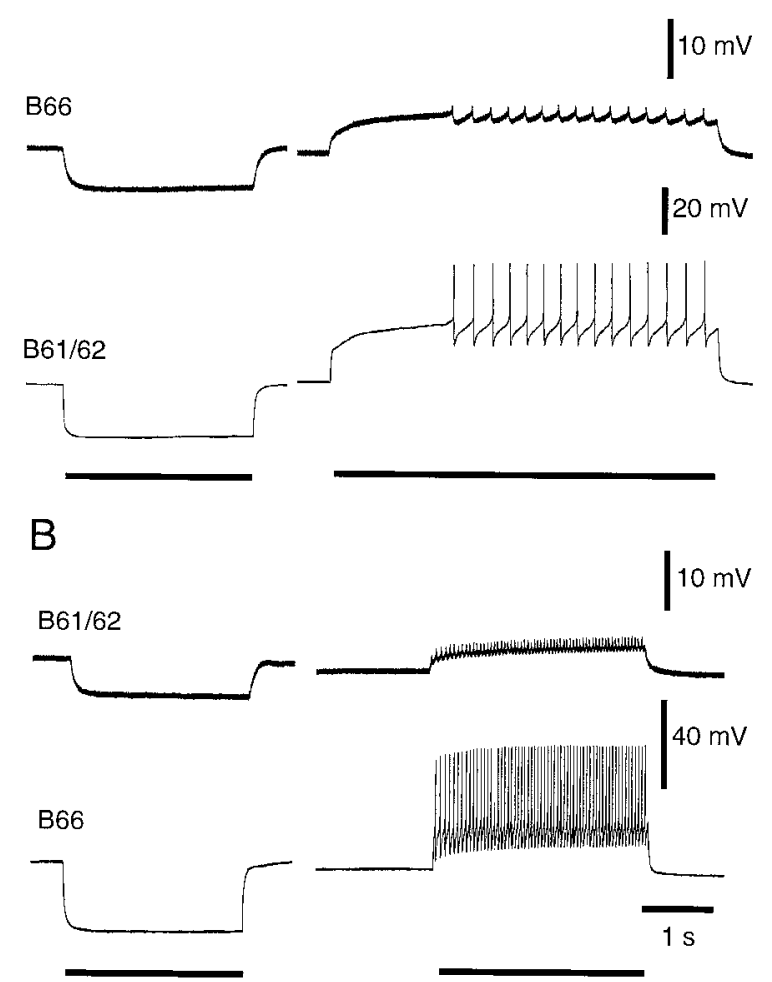

Figure 3. Neurons B66 and B61/62 are electrically coupled. A, Left, In normal ASW hyperpolarizing current injected into B61/62 (horizontal bar under bottom trace) resulted in a hyperpolarization of B66 (top trace). Right, When depolarizing current was injected into B61/62 in a lowcalcium solution, which blocks synaptic transmission, depolarization and coupling potentials were still apparent in B66. $B$, The same manipulations with current injected into B66 are shown. (This experiment was performed with two electrodes in the neuron that was hyperpolarized or depolarized and one electrode in the "follower" neuron.).

neuron to be described that produces radula opening, we compared movements evoked by B66 with those evoked by stimulation of the previously described radula opener motor neuron B48 (Church and Lloyd, 1994). We found that the muscles innervated by B48 simultaneously triggered both protraction and opening [as has been described (Evans et al., 1996)], whereas the muscles innervated by B66 caused the radula to open without protraction. Additionally movements evoked by B48 were bilateral [as has been reported (Evans et al., 1996)], whereas movements evoked by B66 were unilateral. Because the movements evoked by the two motor neurons differ, the movements seen in response to stimulation of B66 could not have resulted from indirect activation of B48 (if B48 had been activated we would have observed protraction in conjunction with opening.).

\section{Activity in B66 and contractions of the SRT during the opening/protraction phase of ingestive motor programs}

To determine whether B66 fires during the opening/protraction phase of ingestive motor programs, we performed experiments in a preparation that consisted of the intact buccal mass and the buccal and cerebral ganglia. A feeding motor program was induced by application of carbachol $\left(10^{-3} \mathrm{M}\right)$ to the cerebral ganglion (Susswein et al., 1996). A video analysis has indicated that 


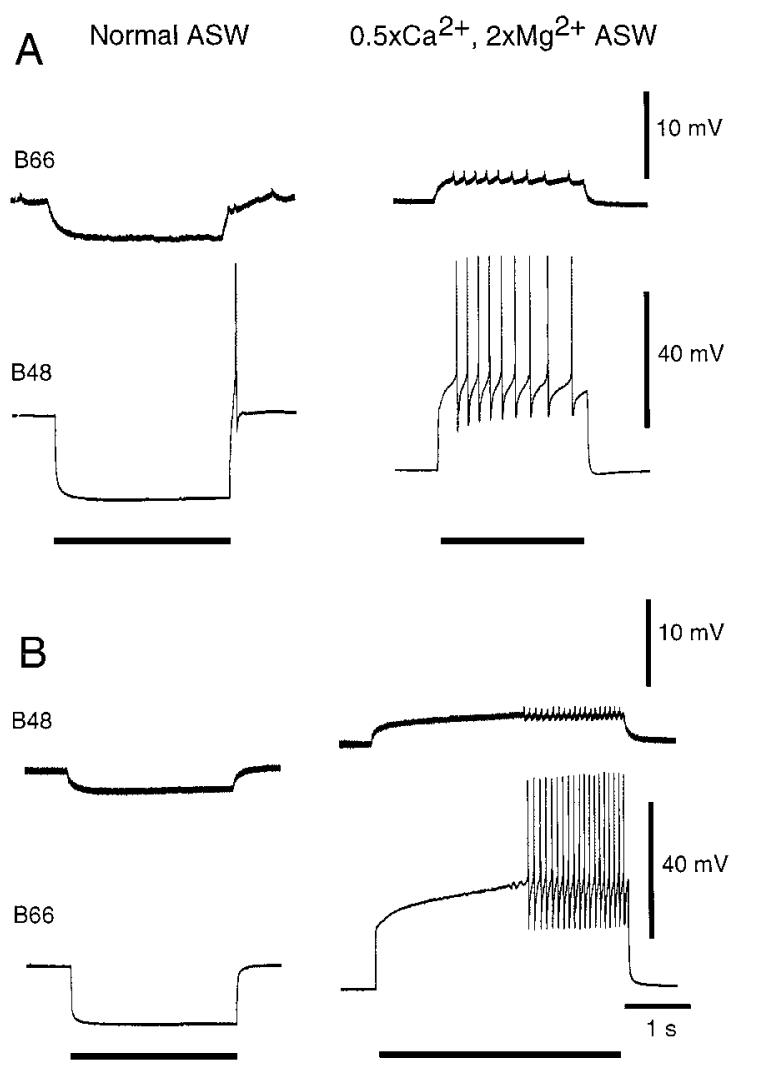

Figure 4. Neurons B66 and B48 are electrically coupled. A, Left, Hyperpolarizing current injected into B48 (horizontal bar under bottom trace) resulted in a hyperpolarization of B66 (top trace). Right, When depolarizing current was injected into B48 in a low-calcium solution, depolarization and coupling potentials were still apparent in B66. B, The same manipulations with current injected into B66 are shown.

motor programs elicited in this manner are predominantly ingestive (Susswein et al., 1996) and are likely to be biting motor programs (Rosen et al., 1997). During carbachol-elicited programs we found that bursts of activity in B66 were out-of-phase with bursts of activity in B4/5 and out-of-phase with highfrequency activity in B8 (Fig. $7 ; n=8$ ). B4/5 and B8 are characterized neurons that predominantly fire during the closing/retraction phase of ingestive motor programs (Rosen et al., 1991; Morton and Chiel, 1993a,b; Church and Lloyd, 1994).

The maximal firing frequency of B66 in these experiments was 15-20 Hz. The minimal firing frequency that elicits a contraction of the SRT in reduced preparations is $3-5 \mathrm{~Hz}(n=10)$. Visual observations of radula movements during carbachol-elicited motor programs also showed that the bursts of activity in B66 were in-phase with opening of the radula halves. Visual observations were confirmed in experiments conducted in a more reduced preparation in which the buccal mass was dissected to expose the SRT so that an isotonic force transducer could be attached to it. Carbachol-induced motor programs were elicited as described above. Contractions of the SRT did indeed occur in-phase with the bursts of activity in B66 (Fig. $7 ; n=5$ ). These data suggest that during ingestive motor programs the SRT receives at least part of its synaptic input from the newly described B66.

Results consistent with this idea were obtained in experiments in which motor programs were elicited by stimulation of CBI-2 [these programs are also mostly ingestive (Rosen et al., 1991; Church and Lloyd, 1994)]. During rhythmic motor programs we

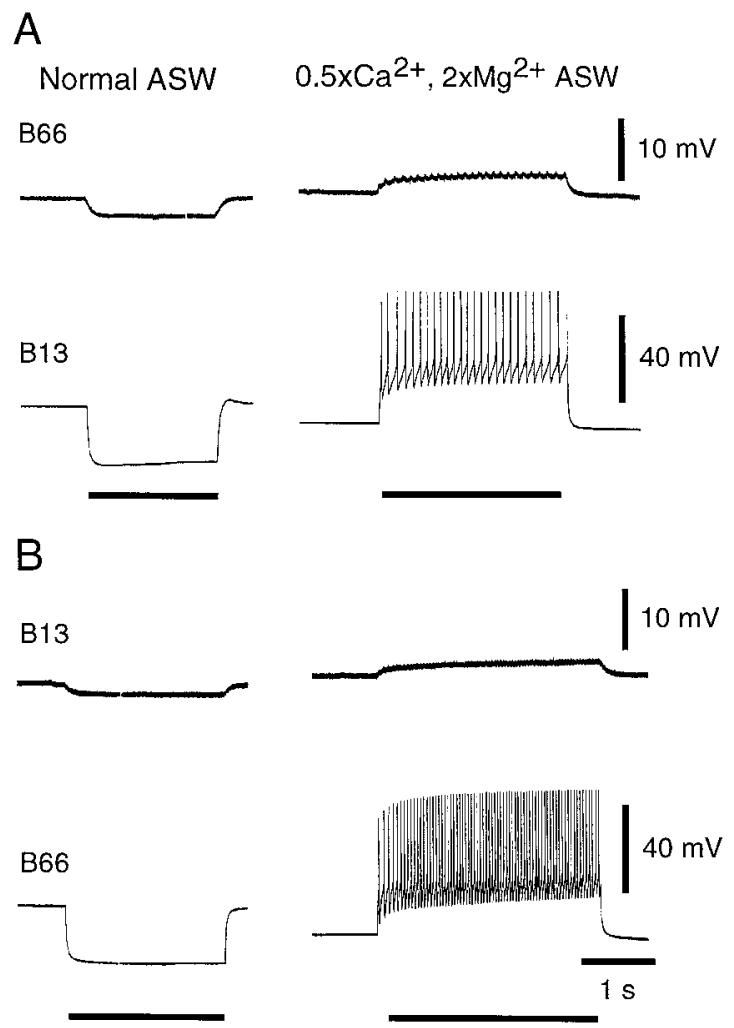

Figure 5. Neurons B66 and B13 are electrically coupled. A, Left, Hyperpolarizing current injected into B13 (horizontal bar under bottom trace) resulted in a hyperpolarization of B66 (top trace). Right, When depolarizing current was injected into B13 in a low-calcium solution, depolarization and coupling potentials were also still apparent in B66. $B$, The same manipulations with current injected into B66 are shown.

decreased the firing frequency of B66 by hyperpolarizing it and observed decreases in the amplitude of contractions of the SRT. When we took this manipulation to the extreme and hyperpolarized the soma of B66 so that we no longer recorded action potentials, contractions were completely eliminated in four out of five experiments (Fig. 8). In one case we reduced contraction size but were unable to eliminate contractions completely.

In previous experiments we have shown that contractions of the SRT can be initiated by shocking both buccal nerve 3 and the radula nerve (Cropper et al., 1996). Because B66 does not have a process in the radula nerve, it is possible that there is another SRT motor neuron (see Discussion for another possibility). If so, these data suggest that this neuron may be electrically coupled to B66. In any case, we do not record SRT contractions during the closing/retraction phase of ingestive motor programs. Thus, if a second SRT motor neuron does exit, it is also likely to be active during radula opening/protraction.

\section{B21 is centripetally activated by B66-induced contractions of the SRT}

Contractions of the SRT induced by extracellular stimulation of buccal nerve 3 elicit centripetal spikes in neuron B21 (Cropper et al., 1996). To determine whether B66-induced contractions of the SRT could elicit similar mechanoafferent activity, we performed experiments in which the motor neuron B66 was identified and filled with fast green dye. The buccal ganglion then could be turned to make B66, which is on the caudal surface of the buccal ganglion, and B21, which is on the rostral surface of the buccal 


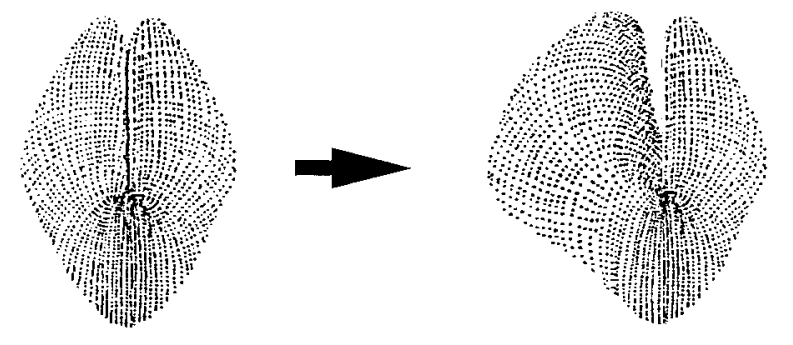

Figure 6. Radula movements observed in a semi-intact preparation as a result of B66 stimulation. Left, Before B66 stimulation. Right, After stimulation. Note that stimulation of B66 results in an ipsilateral movement in which one-half of the radula moves away from the midline.

ganglion, available simultaneously. In most cases we had to remove neurons, e.g., B3 and sometimes B6, to impale both B66 and B21. Stimulation of B66 elicited contractions of the SRT that triggered a series of presumably centripetal spikes in B21 when B66 was stimulated in a physiological manner. Most of these spikes were recorded just before the peak amplitude of the contraction (Figs. 9, 10; $n=10$ ). When B66 was stimulated at an unphysiologically low frequency so that the SRT contracted very slowly, spikes were not observed in B21 (Fig. 10). Interestingly the SRT contracts rapidly during the opening/protraction phase of ingestive motor programs (Figs. 7, 8). We show, therefore, that the change in length of the SRT that occurs during a normal rhythm is likely to elicit spikes in B21.

To confirm that B21 action potentials were indeed centripetal responses to muscle contraction, the buccal ganglion was isolated from the periphery; i.e., it was placed in a separate subchamber. The normal ASW in the ganglion subchamber was then replaced with low-calcium ASW. Spikes remained in B21 despite the fact that central synaptic activity was abolished (Fig. 9A;n=6). When B21 was hyperpolarized, action potentials became smaller in size as would be expected for centripetal spikes (Fig. 9B; $n=4)$.

\section{Peripheral activity of B21 during ingestive motor programs}

Previous studies have shown that radula mechanoafferent neurons are active during the closing/retraction phase of ingestive motor programs (Miller et al., 1994; Rosen et al., 2000b). The data described above suggest that B21 may also be centripetally activated as the SRT contracts as a result of B66 activity, which will occur during the radula opening/protraction phase of behavior. We obtained data that are consistent with this idea in experiments in which we recorded the activity of neuron B21 during carbachol-induced motor programs in semi-intact buccal mass preparations. In these experiments the buccal mass was perfused with ASW, which generally enhances muscle contractions. Additionally the integrity of the peripheral innervation of B21 was verified before carbachol application (i.e., action potentials were recorded in B21 when the radula was touched). Under these conditions B21 did indeed spike during the opening/protraction phase of the motor program as it did during the closing/retraction phase (Fig. 11; $n=7$ ). In addition to full-blown spikes, we also recorded low-amplitude potentials in B21 during radula opening/ protraction. These potentials are likely to be coupling potentials from other radula mechanoafferents or blocked spikes that have been initiated in processes of B21 (Cropper et al., 1996).

To determine whether spikes recorded in B21 during opening/ protraction were likely to be centripetally generated as a result of
B8

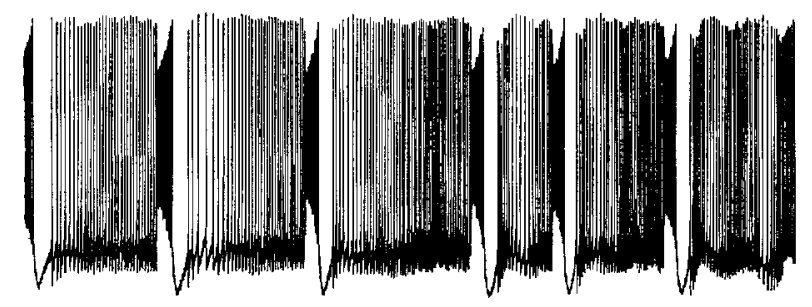

$\mathrm{B} 4 / 5$

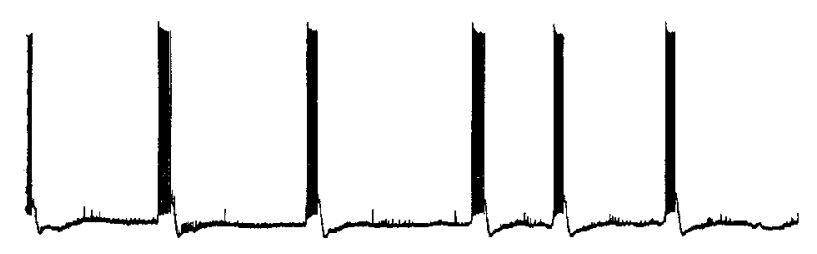

B66

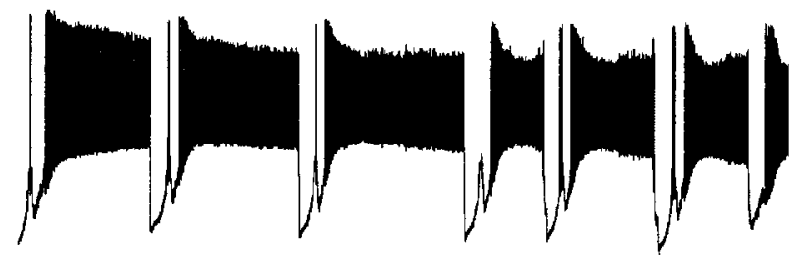

SRT length

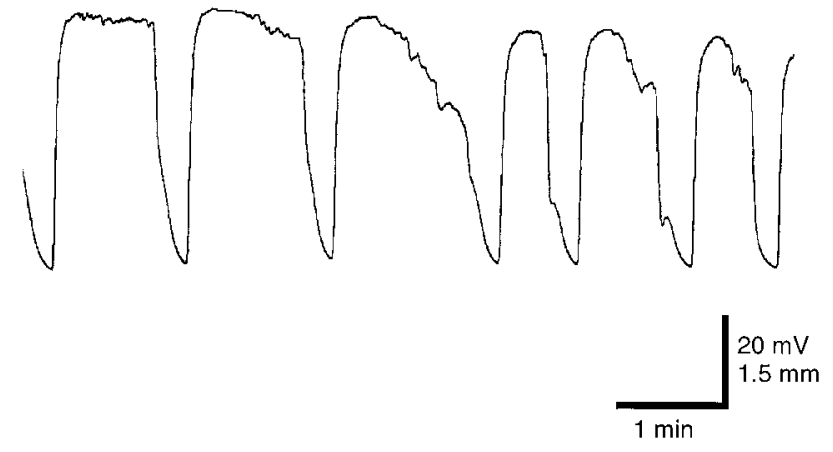

Figure 7. Contractions of the SRT occur during the opening/protraction phase of ingestive motor programs. A motor program was elicited by applying carbachol $\left(10^{-3} \mathrm{M}\right)$ to the cerebral ganglion, which was in an isolated subchamber. The top three traces are intracellular recordings from B8 (a motor neuron that produces radula closing), B4/5 (a multifunction neuron active during the radula closing/retraction phase of behavior), and B66. The bottom trace shows contractions of the SRT measured with an isotonic force transducer. Contractions of the SRT and activity in B66 were out-of-phase with activity in B4/5 and high-frequency activity in B8.

B66-induced contractions of the SRT, we elicited motor programs and indirectly manipulated the membrane potential of B66 by hyperpolarizing B61/62. We did not attempt to hyperpolarize B66 directly because, as discussed above, B21 and B66 are on opposite sides of the buccal ganglion and often cannot be simultaneously impaled without removing neurons. We found that when neuron B61/62 was strongly hyperpolarized, full-blown spikes either were not observed in B21 (Fig. 11; $n=2$ out of 5) or were decreased in number (by an average of $60 \% ; n=3$ out of 5 ). Thus, this observation is consistent with the idea that B21 activity observed during the opening/protraction phase of behavior is at least partially generated peripherally as a result of contractions of the SRT. 


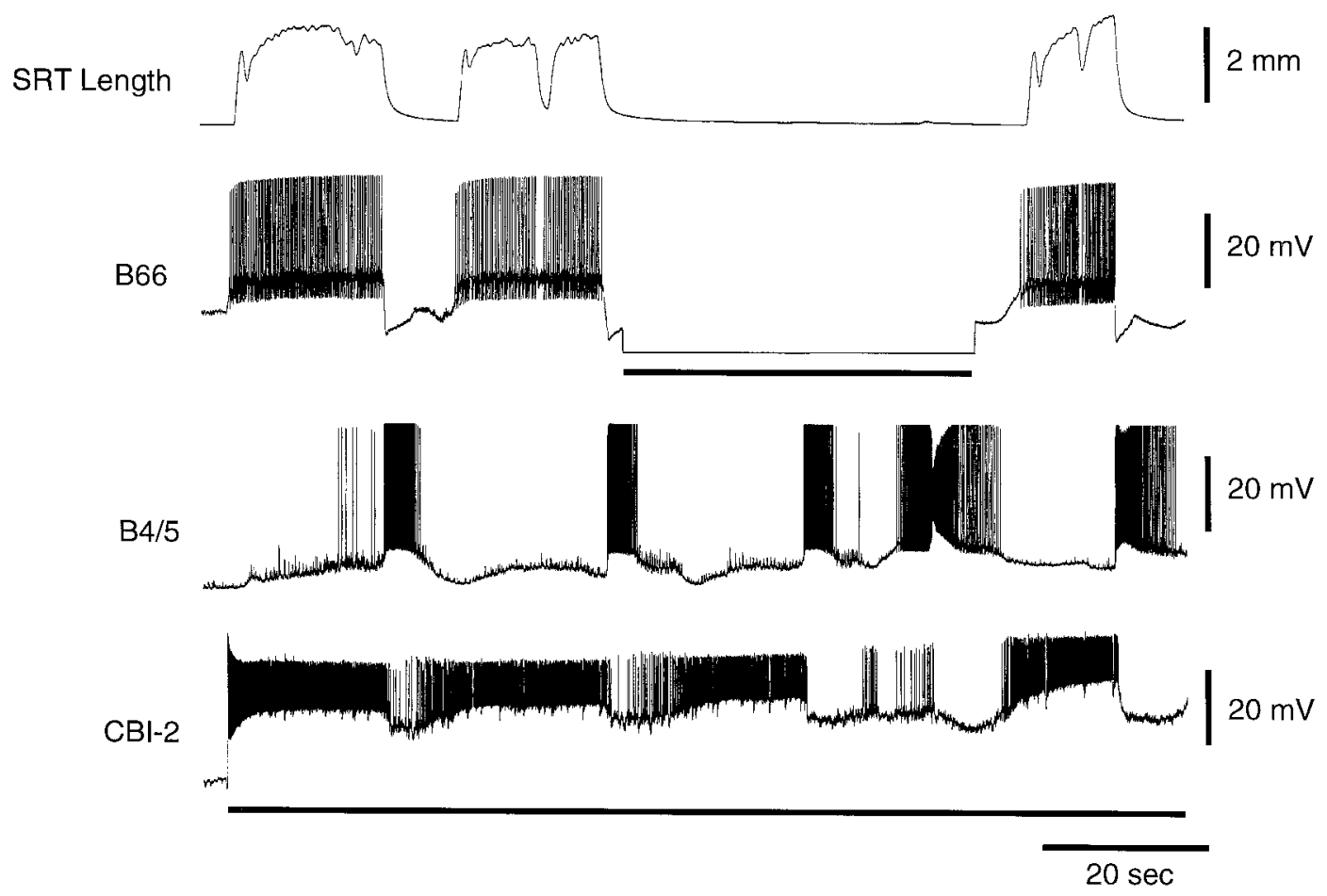

Figure 8. Hyperpolarization of B66 changes the size of SRT contractions during ingestive motor programs. Injecting depolarizing current into the command-like neuron CBI-2 induced a motor program. The bottom three traces are intracellular recordings from CBI-2, B4/5, and B66. The top trace shows contractions of the SRT measured with an isotonic force transducer. During one cycle of the program B66 was hyperpolarized. In four out of five preparations contractions of the SRT were not observed while B66 was hyperpolarized. In one preparation contractions of the SRT were reduced in size but not completely abolished. When hyperpolarization of B66 was released, SRT contractions returned.
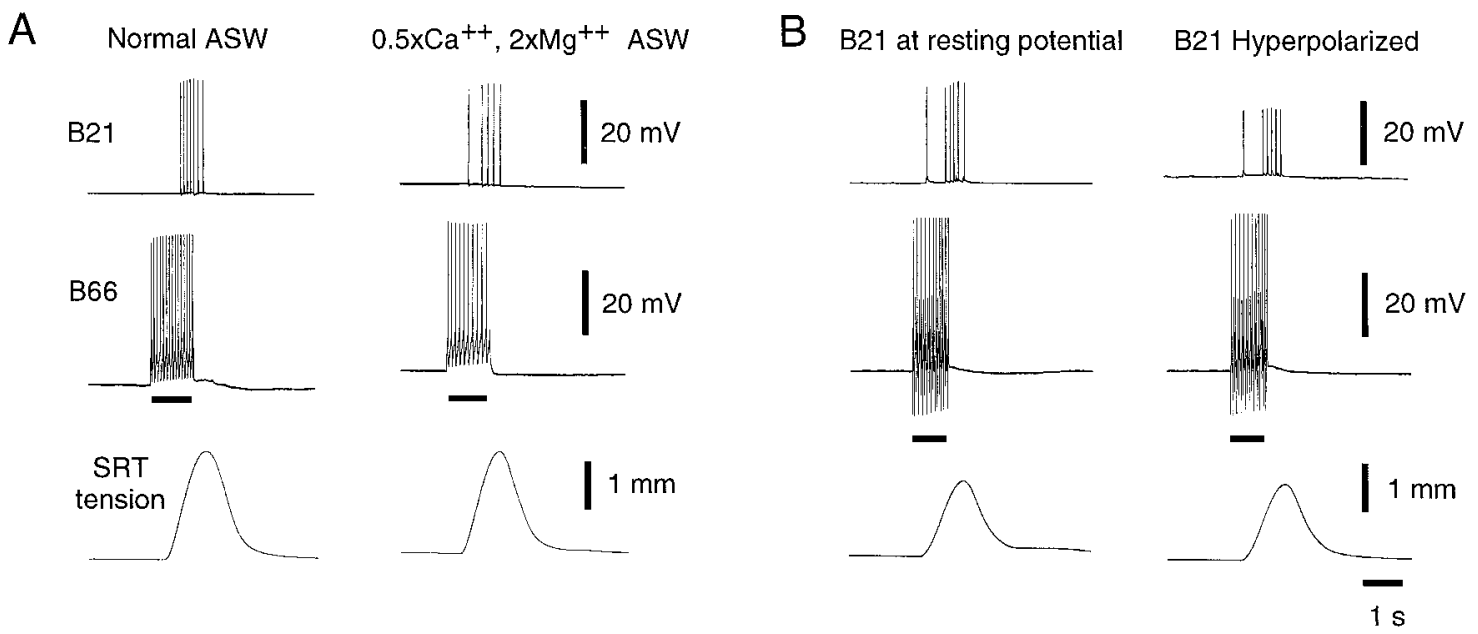

Figure 9. Stimulation of B66 elicits contractions of the SRT and centripetal spikes in B21. A, Left, B66 was stimulated (horizontal bar under middle trace), and corresponding contractions of the SRT were monitored with an isotonic force transducer (bottom trace). Activity in the sensory neuron B21 (top trace) was observed. Right, This activity persisted when the buccal ganglion was placed in a low-calcium solution, indicating that B21 responses can be recorded in the absence of central synaptic activity. B, Left, B21 at resting potential is shown. Right, B21 was hyperpolarized. Note that when B21 was hyperpolarized spikes became smaller, as would be expected if they were centripetally generated.

\section{Centripetal activity in B21 and responses in follower neurons}

Data described above indicate that B21 will be peripherally activated during the opening/protraction phase of ingestive motor programs, i.e., during the phase of behavior in which these neurons are not simultaneously depolarized by input from the CPG. Previous studies have, however, demonstrated that postsynaptic potentials (PSPs) are larger in one of B21's follower neurons, B8, if B21 is simultaneously depolarized (Rosen et al., 2000a) (also see Fig. 16A). [B21 and B8 make a chemical excitatory connection (Klein et al., 1998).] This is also apparent when B21 is peripherally activated (Rosen et al., 2000a) (also see Fig. 16B). Thus centripetally generated spikes in B21 are not likely to be transmitted to one postsynaptic follower (B8) during radula opening/ protraction if $\mathrm{B} 21$ is at its resting membrane potential.

Will B21 actually be at its resting membrane potential during 
2 spikes B66

6 spikes $B 66$

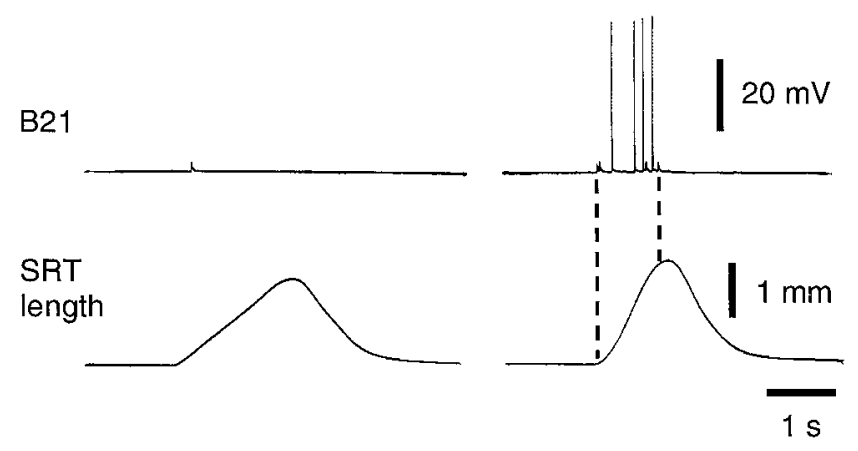

Figure 10. Centripetal spikes in B21 occur as the SRT contracts, unless tension is developed slowly. SRT contractions were elicited when B66 was stimulated so that it generated two spikes or six spikes. (Action potentials in B66 are not shown.) Left, Two spikes in B66 generated an SRT contraction in which tension developed slowly. Under these conditions centripetal spikes were not triggered in B21. Right, In contrast, six spikes in B66 generated a contraction with a faster contraction rate, and action potentials were observed in B21 during the time that the SRT was contracting. Dashed lines facilitate the alignment of spikes in B21 and the SRT contraction. Left and right are from the same preparation.

the opening/protraction phase of behavior? In experiments such as the one shown in Figure 11 spikes are observed in B21 during radula opening/protraction, but B21 neurons are close to their resting membrane potential when these spikes are observed. It is possible however that SRT contractions triggered by motor programs in semi-intact preparations are not as vigorous as SRT contractions in intact animals engaged in normal feeding. Indeed the radula does not open and protract through the jaws in semiintact preparations (Evans and Cropper, 1998) as it does in intact animals (Kupfermann, 1974). This difference in movements may be important because slow waves of depolarization are observed when B21 is vigorously activated by a peripheral stimulus (as it may be under physiological conditions) (Miller et al., 1994). It is possible therefore that B21 neurons will be more depolarized during radula opening/protraction under physiological conditions than is apparent in semi-intact preparations. It would seem unlikely, however, that central depolarizations would be as large as the $15-20 \mathrm{mV}$ generally needed to make PSPs in B8 apparent.

In this study we therefore sought to explore another possibility, that central depolarizations might be less important for B21 to transmit information to other follower neurons. Although the mechanism that "gates in" centripetal activity to B8 has not been characterized, anatomical features of B21 could be important in this context. Namely, B21 is a bipolar or pseudobipolar cell with major lateral and medial processes (Rosen et al., 2000b) (Fig. 12; also see Fig. 14). Its medial process branches and terminates in the ipsilateral buccal hemiganglion and in the periphery (i.e., in the SRT). B21's lateral process terminates in the buccal ganglion in the vicinity of B8 (Rosen et al., 2000b). Previous data suggest that B21 makes contact with B8 via its lateral process (Rosen et al., 2000b). It is possible therefore that because centripetal spikes are relayed centrally they are progressively attenuated if B21 is not centrally depolarized. For example, the soma of B21 is an obvious region of low safety factor for spike conduction. When B21 is not depolarized, spikes actively generated in the medial process may therefore only be electrotonically transmitted through the soma and lateral process and may progressively decrease in size so that transmitter release does not occur at the B8 contact.

To determine whether central depolarizations are less important for B21 to transmit information to other followers, we first sought to determine whether the medial and lateral processes of B21 do in fact predominantly contact different follower neurons. Specifically, we sought to confirm that the lateral process of B21 does in fact contact B8 and sought to determine whether more medial processes of $\mathrm{B} 21$ contact other neurons. We therefore stimulated B21 and recorded PSPs in B8 neurons. We then made a lesion in B21's lateral process and found that PSPs in B8 were not observed if B21 was stimulated at a low enough frequency to resolve individual responses (Fig. $13 B 1$ vs $B 2 ; n=5$ ). In contrast, when this experiment was repeated with a second follower cell, the interneuron B64 (Hurwitz and Susswein, 1996), we found that coupling potentials in B64 were less dramatically affected by lesions of B21's lateral process (Fig. $13 A 1$ vs $A 2 ; n=5$ ). [The connection between B21 and B64 is predominantly electrical (Rosen et al., 2000a). B64 does not make a connection with B8.]

In some experiments we verified that lesions had been effective by injecting B21 neurons with carboxyfluorescein dye. In initial experiments of this sort we wanted to be able to compare the appearance of lesioned neurons with that of neurons that had not been lesioned so we took advantage of the fact that there are two bilaterally symmetrical B21 neurons. One cell was lesioned and used for physiology; the other cell was not lesioned. We then injected both cells. The lateral processes of normal cells were in fact strikingly different from the lateral process of lesioned cells (Fig. 14). In other experiments neurons were injected with fast green dye before physiological experiments. In these cases lesions could be visualized directly.

These data suggest that the B21-B8 connection has a larger lateral component than does the B21-B64 connection. As discussed above, differences in the site of contact of follower neurons could be important if centripetal spikes are progressively attenuated as they are relayed through B21. To determine whether this occurs, we peripherally stimulated B21 and simultaneously recorded responses from different regions in B21. To accomplish this, fast green dye was injected into the soma of B21 so that medial and lateral processes could be visualized and penetrated with a microelectrode. Electrodes in B21 processes were generally 150-300 $\mu \mathrm{m}$ medial or lateral to the B21 soma. When we simultaneously recorded from the medial process and from the soma of B21, we found that somatic spikes were in fact smaller than medial spikes, if B21 was at its resting membrane potential (Fig. $15 A 1 ; n=3)$. Moreover, lateral spikes were smaller than somatic spikes (Fig. $15 B 1 ; n=3$ ). When B21 is at its resting potential, therefore, spikes do in fact appear to be progressively attenuated. When the soma of B21 is depolarized, somatic and lateral spikes can be increased in size (Fig. $15 A 1$ vs $A 2, B 1$ vs $B 2$ ).

The experiments described above suggest, therefore, that central depolarizations in B21 might be less important for relaying information to B64 than they are for relaying information to B8. Spikes do appear to be attenuated as they are relayed through B21, and the B21 contact with B64 appears to involve medial parts of B21. To determine whether there are in fact differences in PSPs recorded in the two neurons, we first performed experiments similar to those described by Rosen et al. (2000a) but monitored activity in both B8 and B64 (Hurwitz and Susswein, 1996). Spikes in B21 were elicited by brief depolarization of its soma at a low frequency (i.e., $1 \mathrm{~Hz}$ ). PSPs in B8 became $\sim 10$ times bigger $(n=$ 4) when B21 was depolarized by $20 \mathrm{mV}$ (Fig. 16 $A$ ), as expected 

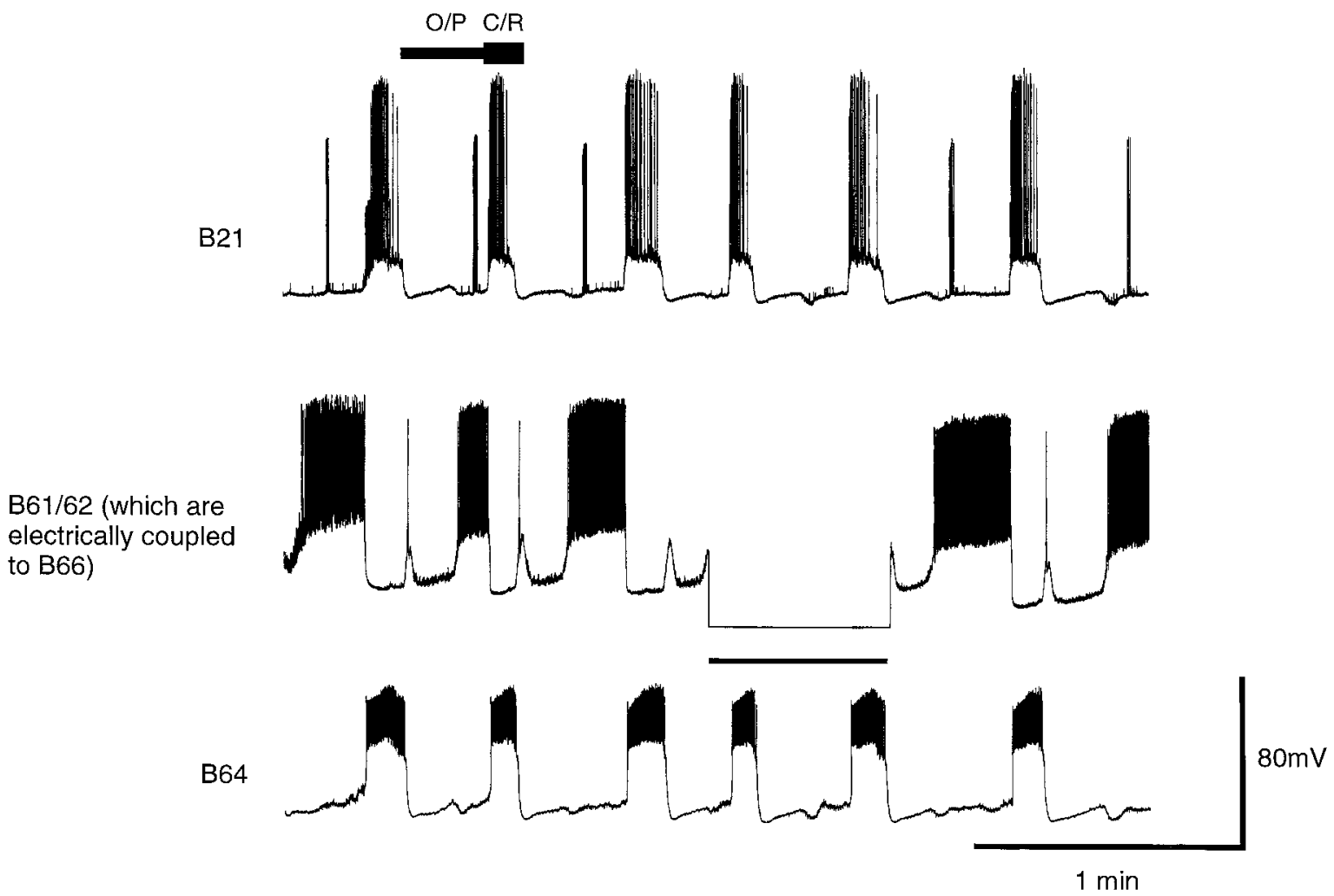

Figure 11. Action potentials are observed in neuron B21 during the opening/protraction phase of ingestive motor programs that are likely to be centripetally generated. An ingestive motor program was elicited by applying carbachol to the cerebral ganglion. The top trace is an intracellular recording from B21, and the middle trace is a recording from B61/62 (a motor neuron that produces radula opening/protraction that is electrically coupled to B66). The bottom trace is an intracellular recording from the radula closing/retraction interneuron B64. Note that action potentials were observed in B21 while B61/62 was active [i.e., during the opening/protraction $(O / P)$ phase of the motor program] and while B64 was active [i.e., during the closing/retraction $(C / R)$ phase of the motor program]. During one cycle of the program B61/62 was hyperpolarized (horizontal bar). Because B61/62 and B66 are electrically coupled, hyperpolarization of B61/62 hyperpolarizes B66. Under these conditions spikes were not observed in B21 during opening/protraction, suggesting that these spikes were generated peripherally as a result of the contraction of the SRT.

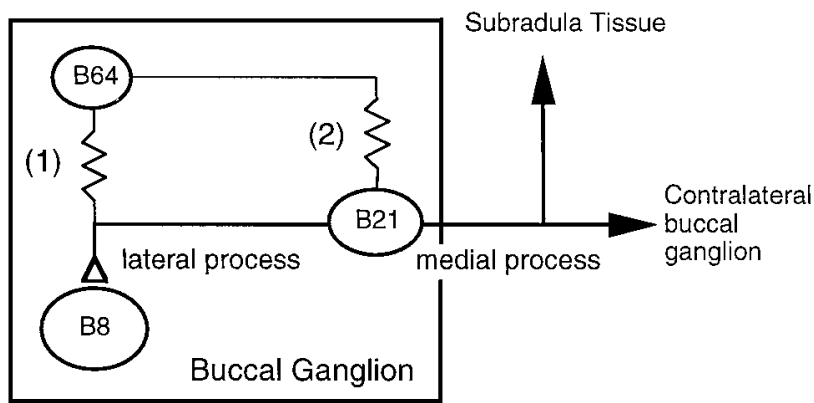

Figure 12. Schematic diagram illustrating contacts between a normal $\mathrm{B} 21$ and B8 and between B21 and B64. Note that B21 is a bipolar or pseudobipolar neuron with a medial process that branches. One branch of the medial process crosses the midline and terminates in the contralateral buccal ganglion; the second branch projects to the periphery (including the SRT). B21's lateral process terminates in the ipsilateral hemiganglion in the vicinity of B8 and B64. Previous data suggest that B21 makes contact with B8 via its lateral process as shown. B21 could make contact with B64 via its lateral process (1), or via a more medial connection (2).

(Rosen et al., 2000a). In contrast, coupling potentials in B64 were less dramatically changed in size by the B21 depolarization $(n=$ 4). More important, we also found differences in the transmission of peripherally generated activity. When we activated B21 by mechanically stimulating the SRT and recorded the resulting responses in B8 and B64, we found that centripetally generated action potentials were effective at eliciting coupling potentials in B64 when B21 was at its resting potential (Fig. 16B; $n=5$ ). In contrast, PSPs were only observed in B8 when B21 was depolarized ( $n=5$ ) as has been described (Rosen et al., 2000a) (also see Fig. 16B). Thus, although centripetal activity does not appear to be transmitted to B8 when B21 is at its resting potential, it does appear to be transmitted to B64.

\section{Functional significance of B21 input to B64 during the opening/protraction phase of ingestive motor programs}

Because B21 (and presumably other radula mechanoafferents) is centripetally activated during opening/protraction and provides excitatory input to the closing/retraction circuitry, it could play an important role in inducing the opening/protraction-to-closing/ retraction phase transition. It is clear, however, that this phase transition can occur in the isolated nervous system, i.e., when radula mechanoafferents are not centripetally activated (e.g., Fig. 17). Nevertheless when the periphery is present and radula mechanoafferents are activated, they could accelerate the activation of B64 and therefore the transition to closing/retraction. In experiments such as the one shown in Figure 11 we reduced centripetal activity in B21 (and presumably other radula mechanoafferents) during opening/protraction. These data do not, however, specifically evaluate the mechanoafferent contribution to phase transitions. Because we injected hyperpolarizing current into opening/ 


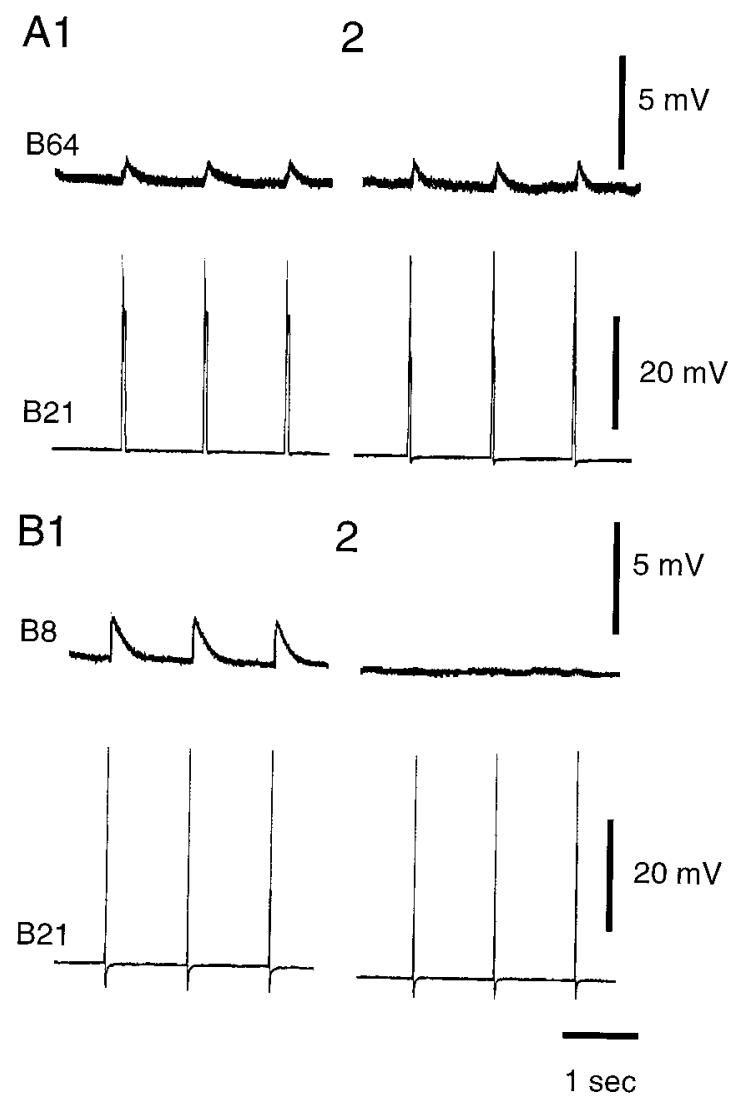

Figure 13. Effect of lesioning the lateral process of B21 on PSPs in B8 $(B)$ and coupling potentials in B64 $(A)$. Spikes in B21 were elicited by brief depolarization of its soma. $A 1, B 1$, Traces before the lateral process was lesioned are shown. $A 2, B 2$, Electrodes were removed from neurons, and the lateral process of B21 was lesioned. Cells were then reimpaled, and responses to stimulation of B21 were recorded. Note that coupling potentials in B64 are not significantly changed in size whereas PSPs in B8 are abolished. $A$ and $B$ are from different preparations. B21 was at its resting potential (approximately $-60 \mathrm{mV}$ ) in both experiments. Both experiments were performed in $3 \times \mathrm{Ca}^{2+}$ ASW so that PSPs would be more visible.

protraction interneurons, we reduced the corresponding inhibition in the closing/retraction circuitry.

To evaluate more specifically the potential impact of centripetal activity in radula mechanoafferents such as B21 on temporal characteristics of motor programs, we performed experiments in which ingestive activity was elicited in the isolated nervous system. We directly controlled radula mechanoafferent spiking with current injection and triggered ingestive motor programs with and without radula mechanoafferent activity during opening/ protraction. We then compared the duration of opening/protraction under the two conditions.

In these experiments we could not precisely mimic physiological activity in the radula mechanoafferent cluster. For example, we are not technically able to characterize radula mechanoafferent-firing patterns in intact animals. (As described above, firing patterns in semi-intact preparations are likely to underestimate centripetal activity in radula mechanoafferents because radula openings are not very vigorous.) We did, however, use the data obtained in semi-intact preparations as a guide in determining stimulation parameters for B21. Specifically, B21 was held at its resting membrane potential, and spikes were triggered with brief current pulses. Moreover, B21 was stimulated after opening/protraction began

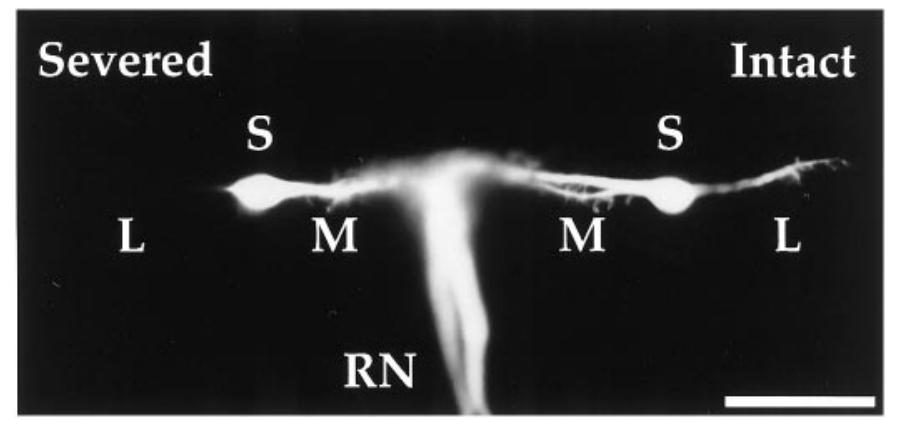

Figure 14. Verification of lesions. Carboxyfluorescein dye was injected into the left and right B21 neurons in a single buccal ganglion at the conclusion of a physiological experiment (see Fig. 13). The lateral process of the left B21 was severed, whereas the right B21 remained intact. The normal morphology of B21 can be seen by looking at the right cell. Note its lateral process $(L)$, its soma $(S)$, and its medial process $(M)$. That the lesion was effective in this experiment can be seen by comparing the lateral processes of the right versus the left B21. RN, Radula nerve. Scale bar, $500 \mu \mathrm{m}$.

because under physiological conditions the SRT has to contract before B21 is activated. Finally, firing frequencies for B21 ranged from 10 to $20 \mathrm{~Hz}$, frequencies that were observed during carbacholinduced programs. B21 was, however, "overstimulated" in that periods of B21 stimulation were longer than durations of B21 activity observed during carbachol-induced motor programs. We overstimulated B21 in these experiments to compensate for the fact that under physiological conditions B64 would not solely receive input from B21; i.e., other radula mechanoafferents would also be activated. In fact coupling potentials are observed in B21 during carbachol-elicited motor programs at times when B21 itself is no longer spiking.

Ingestive activity was elicited by CBI-2 because carbacholinduced motor programs often do not cycle regularly even when CPG elements are not manipulated (e.g., Fig. 7). More specifically, CBI-2 was stimulated so that single two-phase cycles of ingestive activity were triggered approximately once every minute. Under these conditions parametric features of individual cycles of the motor program are highly reproducible. When B21 was stimulated the duration of the opening/protraction phase of the motor program was reduced. Specifically when B21 was stimulated at $20 \mathrm{~Hz}$ the duration of opening/protraction was on average reduced by $44 \%$ (range, $18-72 \% ; n=6$; Fig. 17), which was a statistically significant reduction (paired two-tailed $t$ test; $p<0.004$ ). When B21 was stimulated at a lower frequency (e.g., $10 \mathrm{~Hz}$ ), the duration of opening/protraction was also reduced, but as might be expected, the effect was less dramatic [i.e., on average, opening/protraction was reduced by $18 \%$ (range, $3-37 \% ; n=4$ )]. Thus, radula mechanoafferent activity during radula opening/ protraction could impact ingestive motor programs.

\section{DISCUSSION}

\section{Identification of an SRT motor neuron}

Although a previous study (Cropper et al., 1996) indicated that the SRT is a muscle, its motor neurons were unidentified. In this study we characterize B66 as an SRT motor neuron. It is likely that the SRT has other motor neurons [as is the case for other muscles in Aplysia (Cohen et al., 1978; Church and Lloyd, 1991; Church et al., 1993; Jordan et al., 1993)]. SRT contractions can be elicited by shocking both buccal nerve 3 and the radula nerve (Cropper et al., 1996), yet B66 only has a process in nerve 3. It is 
A1

Resting Membrane Potential

Medial Process

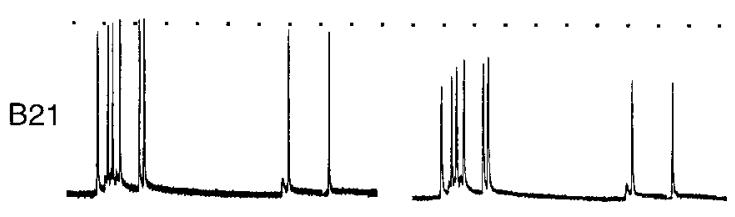

B1

Resting Membrane Potential

Lateral Process

B21
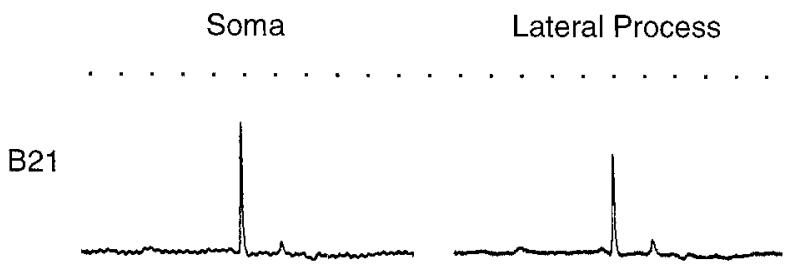

A2

Soma Depolarized by @15 mV

Medial Process

Soma
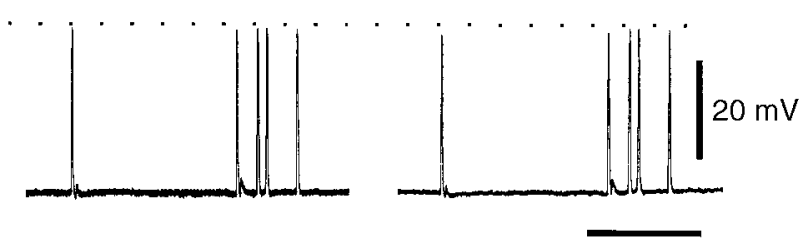

$500 \mathrm{msec}$

B2

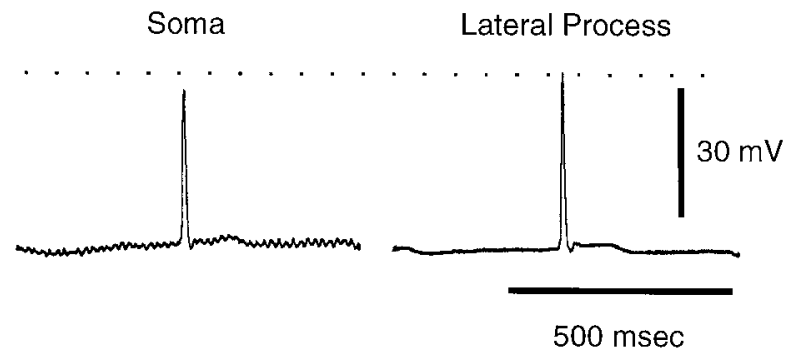

Figure 15. Centripetal spikes are attenuated in the soma and lateral process of B21 when it is at its resting membrane potential. $A 1$, Centripetal spikes were triggered when B21 was at its resting membrane potential (approximately $-60 \mathrm{mV}$ ). Left, Resulting responses were recorded from the medial process of B21 (i.e., $\sim 200 \mu \mathrm{m}$ from the soma). Right, Responses were also simultaneously recorded from the soma of B21. Note that responses recorded from the soma are smaller in amplitude. $A 2$, Centripetal spikes were triggered when B21 was depolarized by $\sim 15 \mathrm{mV}$. Left, Responses recorded from the medial process are shown. Right, Responses recorded from the soma are shown. Note that responses are now similar in amplitude. Recordings shown in $A 1$ and $A 2$ were made from the same preparation. The dotted lines facilitate amplitude comparisons. B1, Centripetal spikes were triggered when B21 was at its resting membrane potential (approximately $-60 \mathrm{mV}$ ). Responses were simultaneously recorded from the soma (left) and the lateral process (i.e., $\sim 175 \mu \mathrm{m}$ from the soma; right). Note that responses recorded from the lateral process are smaller. B2, Centripetal spikes were triggered when B21 was depolarized by $\sim 15$ $\mathrm{mV}$. Left, A response from the soma is shown. Right, A response from the lateral process is shown. Note that both spikes are increased in amplitude. Recordings shown in $B 1$ and $B 2$ were made from the same preparation. Recordings in $A$ and $B$ are from two different preparations.

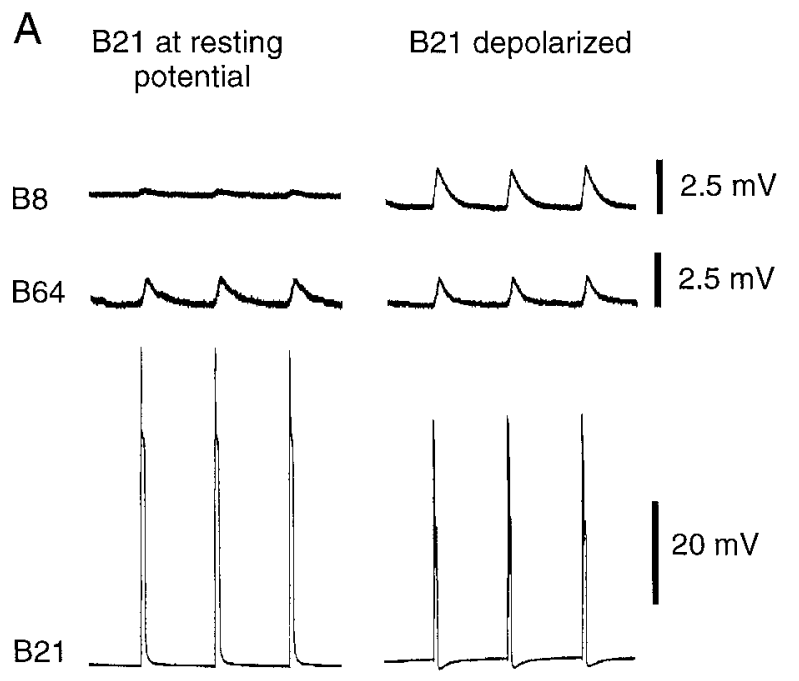
B B21 at resting potential
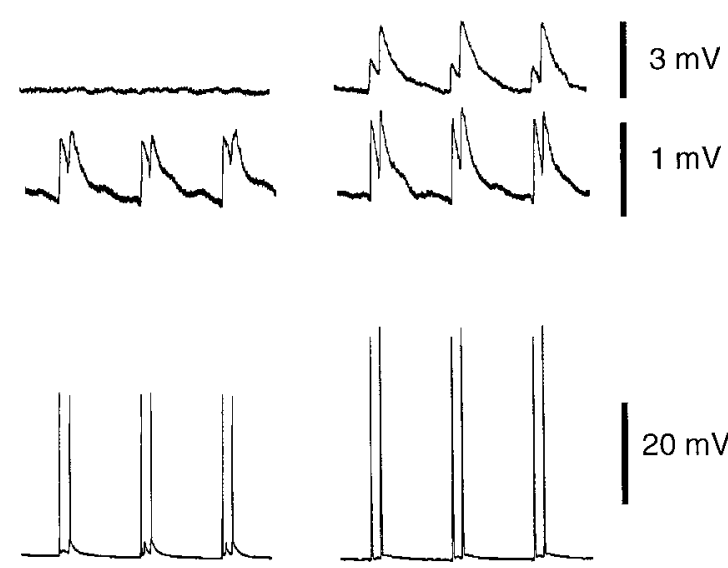

B21 depolarized

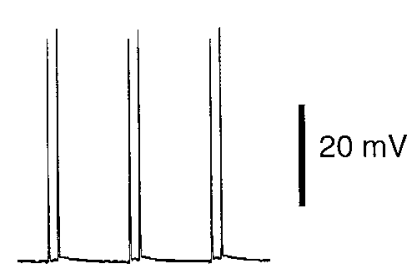

1 sec

Figure 16. Central depolarization increases the size of B21-induced PSPs in B8 but less dramatically alters the size of B21-induced coupling potentials in B64. $A$, Spikes in B21 were elicited by brief depolarization of its soma. Left, B21 was at its resting potential (i.e., approximately $-60 \mathrm{mV}$ ). Right, B21 was depolarized by $20 \mathrm{mV}$. B, Spikes in B21 were elicited by mechanical stimulation of the SRT. Left, B21 was at its resting potential. Right, B21 was depolarized by $20 \mathrm{mV}$.

possible, however, that SRT contractions elicited by radula nerve stimulation do not result from the activation of a process of a motor neuron. The radula nerve contains neuronal processes that are 5-HT immunoreactive and processes that are SCP immuno- reactive (Lloyd et al., 1987; Miller et al., 1994; Alexeeva et al., 1998). When 5-HT and SCP are exogenously applied, stretchinduced contractions of the SRT are triggered (Cropper et al., 1996). 

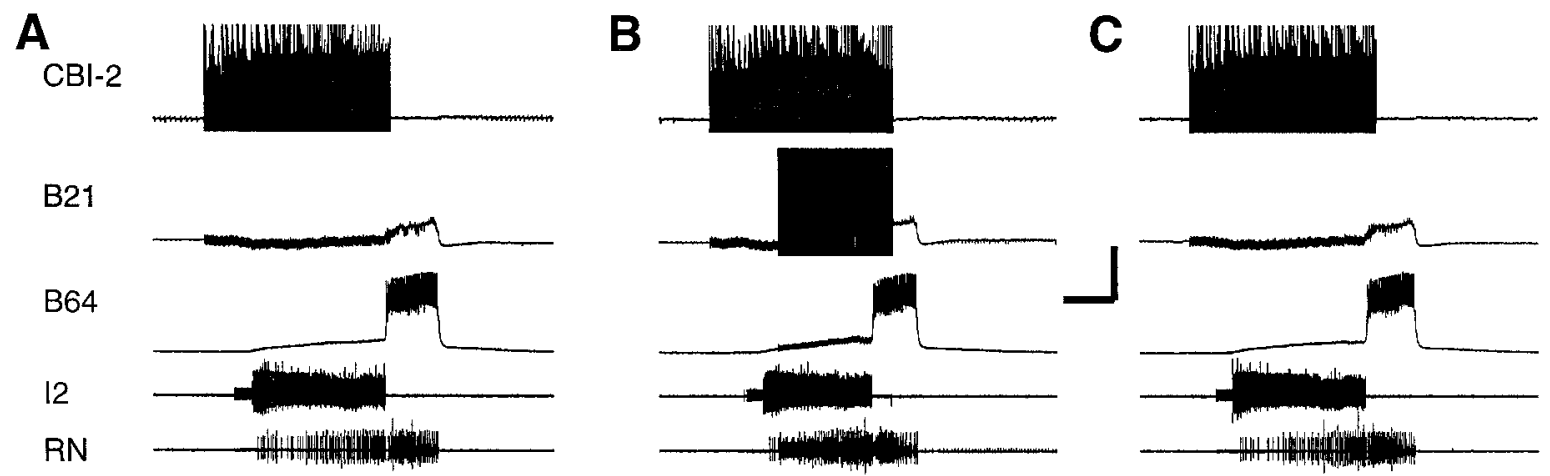

Figure 17. Activity in B21 during the radula opening/protraction phase of an ingestive motor program can affect temporal characteristics of the motor program. Ingestive activity was induced when CBI-2 was intracellularly stimulated with brief pulses in bursts (top row of traces). CBI-2's intraburst firing frequency was $8 \mathrm{~Hz}$, and bursts were elicited approximately once a minute. That widespread activity was indeed triggered in the feeding circuitry can be seen from the intracellular recording from B21 (second row of traces from the top), from the intracellular recording from B64 (third row of traces from the top), from the extracellular recording from the I2 nerve (fourth row of traces from the top), and from the extracellular recording from the radula nerve $(R N$; bottom row of traces). The duration of the opening/protraction phase of the motor program was monitored via the extracellular recording from the I2 nerve, which contains the processes of the opening protraction interneurons and motor neurons B61/62 and B31/32. The closing/retraction phase of the motor program is most clearly marked by the activity in B64. As is apparent in $A-C$ this type of CBI- 2 stimulation triggers one cycle of a two-phase motor program. $A$, Control (i.e., current was not injected into B21) traces are shown. B21 receives depolarizing input during closing/retraction but does not spike. $B$, B21 was stimulated with brief current pulses at $20 \mathrm{~Hz}$ after the initiation of opening/protraction. B21 stimulation was terminated shortly after the retraction phase was initiated. Note that the duration of the opening/protraction phase of the motor program was reduced. $C$, Ingestive activity was again triggered without spiking in B21. The duration of opening/protraction returned to its control value. Calibration: vertical, $40 \mathrm{mV} ;$ horizontal, 5 sec.

\section{SRT contractions during ingestive motor programs}

Aplysia ingestive motor programs are induced by stimulating the command-like neuron CBI-2 (Rosen et al., 1991) or by applying carbachol to the cerebral ganglion (Susswein et al., 1996). Both methods have been used in semi-intact preparations in which movements have been monitored (Susswein et al., 1996; Rosen et al., 1997; Evans and Cropper, 1998). These experiments have shown that CBI-2 and carbachol generally induce biting motor programs. With both methods we show that B66 is active during the opening/protraction phase of the motor program. As discussed above there may be as yet uncharacterized SRT motor neurons. If such neurons exist they are also likely to be active during opening/protraction because SRT contractions were only observed at this point. Our data suggest, therefore, that during biting motor programs B21 could only function as a proprioceptor during radula opening/protraction.

\section{Radula mechanoafferent input to B64}

Centrally induced depolarizations are important if afferent activity in B21 is to be transmitted to B8 (Rosen et al., 2000a,b). Centrally induced depolarizations are recorded from B21 during radula closing/retraction but are not recorded during opening/ protraction. Because proprioceptive activity in B21 occurs during opening/protraction, a question we addressed was the following: are centrally induced depolarizations necessary for the transmission of centripetal activity to other B21 followers? B64 was of interest because it presumably plays an important role in terminating opening/protraction and initiating closing/retraction (Hurwitz and Susswein, 1996). The processes that determine when B64 will be activated are likely to determine temporal characteristics of motor programs.

B64 is presumably activated by input from other cells. It does not fire spontaneously, and it does not show postinhibitory rebound when it is close to its resting membrane potential (Hurwitz and Susswein, 1996). Moreover, depolarizations that appear to be PSPs are observed in B64 when it begins to spike during motor programs (Hurwitz and Susswein, 1996; Baxter et al., 1997). We now show that B21 [and presumably other radula mechanoafferents (Miller et al., 1994)] is likely to be one source of excitatory input to B64. Radula mechanoafferents do not, however, appear to act alone to trigger activity in B64. B64 is activated in the isolated nervous system, where radula mechanoafferents cannot be centripetally activated. Thus, it is likely that B64 integrates input from mechanoafferents with input from other neurons. The current model of the feeding CPG includes a "cell Z," which triggers B64 activity when only central activity is modeled (Baxter et al., 1997). Our data suggest, however, that under physiological conditions B64 additionally receives input from B21, which contributes to its activation.

\section{Central influences on radula mechanoafferent transmission}

Central modulation of afferent input to a CPG has been extensively described (Sillar, 1991; Pearson, 1993; Wolf and Burrows, 1995; Busches and El Manira, 1998; El Manira et al., 1998; Rossignol et al., 1998; DiCaprio, 1999). Although modulation of sensory input to CPGs occurs in many preparations, underlying cellular mechanisms are still being characterized (Sillar, 1991; Pearson and Ramirez, 1997). One mechanism involves phasic, centrally induced depolarizations of sensory neurons that "gate out" centripetal activity (Wolf and Burrows, 1995; Cattaert and Clarac, 1998; Redman, 1998), often because they are chemically mediated and increase sensory neuron conductance (Cattaert and Clarac, 1998; Redman, 1998). In B21, however, depolarizations result, at least in part, from electrical coupling with patterngenerating interneurons and gate in afferent activity (Rosen et al., 2000b). The cellular mechanisms that gate in centripetal activity in B21 have not been completely characterized. Data (Rosen et al., 2000a,b) suggest, however, that B21 may be similar to other Aplysia neurons in which tonic depolarization of the presynaptic terminal results in a graded increase in transmitter release (Shapiro et al., 1980).

This study describes a second factor that may contribute to gating in B21. Namely, B21 may be similar to neurons that have 
been described in which spikes generated at one site are not propagated throughout the neuron (Mulloney and Selverston, 1972; Meyrand et al., 1992). To elaborate, although its medial process is centripetally activated, we show that B21 contacts B8 via its lateral process. Other data suggest that the lateral process also contacts other followers (Rosen et al., 2000a). If centripetal activity in B21, which is generated in the medial process, is to reach neurons contacted via the lateral process, it must pass through B21's soma (a potential region of low safety factor). We show that centripetal spikes in B21's soma are in fact attenuated. Thus, they have presumably been generated in the medial process and are electrotonically conducted to the soma. Our data also suggest that attenuation continues because spikes in the lateral process of B21 are smaller than somatic spikes. Spikes that reach regions of the lateral process where synaptic contacts are made may be quite small. Central depolarizations could gate in afferent activity by overcoming the low safety factor of transmission from the medial process to the soma. With central depolarizations spikes may be actively generated closer to release sites and consequently may be larger.

We show that B64 differs from B8 in that B21 does not predominantly contact B64 via its lateral process. This does not, however, make B64 insensitive to central depolarizations in B21. Coupling potentials in B64 are larger when B21 is centrally depolarized (possibly because the B64 contact with B21 is made on the soma of B21). More important, because the B21-B64 contact is predominantly electrical, centrally induced DC depolarizations in B21 are transmitted to B64. Consequently, B64 is like B8 in that it will be most effectively driven by B21 when B21 is centrally depolarized. Why then does B64 contact medial parts of B21 despite the fact that its soma is closer to B21's lateral process (Hurwitz and Susswein, 1996)? The above hypothesis suggests one advantage of the medial contact. Although B64 appears to contact B21 at a site where some spike attenuation has occurred, this attenuation is presumably less than it would be if the contact were made more laterally. To summarize, B64 and B8 are both most effectively driven when B21 is centrally polarized. The two cells differ, however, in that the input to B64 appears to be regulated in a graded manner. In contrast, the input to B8 appears to be almost completely gated in by central depolarization; i.e., it is gated in an unambiguous manner [see DiCaprio (1999) for a more extensive discussion of this idea]. To be specific, we did see postsynaptic responses in B64 when B21 was at its resting membrane potential and somatic spikes were attenuated. B64 postsynaptic responses did, however, increase in amplitude when B21 was centrally depolarized. In contrast, we only recorded postsynaptic responses in B8 when B21 was centrally depolarized. Thus, B21 has been referred to as having multiple "output states" (Rosen et al., 2000a). It apparently can provide input to B64 alone, or it can provide input to both B8 and B64.

\section{B21 as a dual function sensory cell}

B21 is an exteroceptor (Rosen et al., 2000a,b). We show that it is also a proprioceptor. Sensory responses to more than one type of stimulus have been described (Newman and Hartline, 1981; Rosen et al., 1982; Wallace et al., 1998). This phenomenon has, however, been most extensively discussed in the context of information integration. This is unlikely to be the primary function of activity in B21. In fact B21's proprioceptive and exteroceptive functions may predominate during different ingestive behaviors. Proprioceptive activity is likely to be most vigorous when radula openings are pronounced. This will occur when animals bite
(Kupfermann, 1974). In contrast, exteroceptive activity is likely to be most vigorous when food is ingested. This will occur when animals swallow (Kupfermann, 1974). Thus, a sensory neuron's ability to respond to more than one type of stimulus can improve its function within a specific context. Additionally, a sensory neuron may act as a dual function cell, particularly when it is like B21 and its output state can be regulated.

When B21 acts an exteroceptor, it is likely to be important for detecting food and producing changes in the activity of the feeding circuitry that are important for its ingestion (Rosen et al., 2000a,b). Our data suggest that when B21 acts as a proprioceptor it may influence temporal characteristics of ingestive motor programs in that when it is vigorously activated it may decrease the duration of radula opening/protraction. As discussed above vigorous proprioceptive activation of B21 may predominantly occur when animals bite because radula openings are most pronounced during this behavior. More specifically, proprioceptive activity in B21 is likely to be enhanced when opener muscles contract rapidly. Under physiological conditions this is likely to occur predominantly when interbite intervals are decreased. To summarize, proprioceptive activity in B21 may be most pronounced when animals bite, particularly when animals bite quickly. Under these conditions proprioceptive activity in B21 may in turn hasten the termination of opening/protraction and the initiation of closing/retraction. Thus, proprioceptive activity in B21 may help coordinate the activity of the feeding CPG with the biomechanical state of the radula [see Pearson (1993) for a more extensive discussion of the role of proprioceptors in coupling CPG activity and the biomechanical state of a peripheral target].

\section{REFERENCES}

Alexeeva A, Borovikov D, Miller MW, Rosen SC, Cropper EC (1998) Effect of a serotonergic extrinsic modulatory neuron (MCC) on radula mechanoafferent function in Aplysia. J Neurophysiol 80:1609-1622.

Baxter DA, Patel VC, Susswein AJ, Bryne J (1997) Computational model of a multifunctional central pattern generator (CPG) that underlies consummatory feeding behavior in Aplysia. Soc Neurosci Abstr 23:1044.

Borovikov D, Rosen SC, Cropper EC (1997) SCP-containing sensory neurons in Aplysia are peripherally activated as a result of motor neuron activity. Soc Neurosci Abstr 23:1045.

Busches A, El Manira A (1998) Sensory pathways and their modulation in the control of locomotion. Curr Opin Neurobiol 18:733-739.

Cattaert D, Clarac F (1998) Presynaptic inhibition in crayfish primary afferents. In: Presynaptic inhibition and neural control (Rudomin P, Romo R, Mendell LM, eds), pp 192-205. New York: Oxford UP.

Church PJ, Lloyd PE (1991) Expression of diverse neuropeptide cotransmitters by identified motor neurons in Aplysia. J Neurosci 11:618-624.

Church PJ, Lloyd PE (1994) Activity of multiple identified motor neurons recorded intracellularly during evoked feedinglike motor programs in Aplysia. J Neurophysiol 72:1794-1809.

Church PJ, Whim MD, Lloyd PE (1993) Modulation of neuromuscular transmission by conventional and peptide transmitters released from excitatory and inhibitory motor neurons in Aplysia. J Neurosci 13:2790-2800.

Cohen JL, Weiss KR, Kupfermann I (1978) Motor control of buccal muscles in Aplysia. J Neurophysiol 41:157-180.

Cropper EC, Kupfermann I, Weiss KR (1990) Differential firing patterns of the peptide-containing cholinergic motor neurons B15 and B16 during feeding behavior in Aplysia. Brain Res 522:176-179.

Cropper EC, Evans CG, Rosen SC (1996) Multiple mechanisms for peripheral activation of the peptide-containing radula mechanoafferent neurons B21 and B22 of Aplysia. J Neurophysiol 76:1344-1351.

Delcomyn F (1980) Neural basis of rhythmic behavior in animals. Science 210:492-498.

DiCaprio RA (1999) Gating of afferent input by a central pattern generator. J Neurophysiol 81:950-953.

Drushel RF, Neustadter DM, Shallenberger LL, Crago PE, Chiel HJ 
(1997) The kinematics of swallowing in the buccal mass of Aplysia californica. J Exp Biol 200:735-752.

El Manira A, Parker D, Krieger P, Wikstrom M, Grillner S (1998) Presynaptic inhibition of synaptic transmission from sensory, interneuronal, and supraspinal neurons to spinal target cells in lamprey. In: Presynaptic inhibition and neural control (Rudomin P, Romo R, Mendell LM, eds), pp 329-348. New York: Oxford UP.

Evans CG, Cropper EC (1998) Proprioceptive input to feeding motor programs in Aplysia. J Neurosci 18:8016-8031.

Evans CG, Rosen S, Kupfermann I, Weiss KR, Cropper EC (1996) Characterization of a radula opener neuromuscular system in Aplysia. J Neurophysiol 76:1267-1281.

Gardner D (1971) Bilateral symmetry and interneuronal organization in the buccal ganglia of Aplysia. Science 173:550-553.

Gardner D (1977) Interconnections of identified multiaction interneurons in buccal ganglia of Aplysia. J Neurophysiol 40:349-361.

Hurwitz I, Susswein AJ (1996) B64, a newly identified central pattern generator element producing a phase switch from protraction to retraction in buccal motor programs of Aplysia californica. J Neurophysiol 75:1327-1344.

Hurwitz I, Goldstein RS, Susswein AJ (1994) Compartmentalization of pattern-initiation and motor functions in the B31 and B32 neurons of the buccal ganglia of Aplysia californica. J Neurophysiol 71:1514-1527.

Hurwitz I, Neustadter D, Morton DW, Chiel HJ, Susswein AJ (1996) Activity patterns of the $\mathrm{B} 31 / \mathrm{B} 32$ pattern initiators innervating the I2 muscle of the buccal mass during normal feeding movements in Aplysia californica. J Neurophysiol 75:1309-1326.

Hurwitz I, Kupfermann I, Susswein AJ (1997) Different roles of neurons B63 and B34 that are active during the protraction phase of buccal motor programs in Aplysia californica. J Neurophysiol 78:1305-1319.

Jahan-Parwar B, Wilson AH, Fredman SM (1983) Role of proprioceptive reflexes in control of feeding muscles of Aplysia. J Neurophysiol 49:1469-1480.

Jordan R, Cohen KP, Kirk MD (1993) Control of intrinsic buccal muscles by motoneurons B11, B15, and B16 in Aplysia californica. J Exp Zool 265:496-506.

Kater SB, Rowell CHF (1973) Integration of sensory and centrally programmed components in generation of feeding activity of Helisoma trivolvis. J Neurophysiol 36:142-154.

Kawahara S, Yano M, Shimizu H (1994) Radular mechanosensory neuron in the buccal ganglia of the terrestrial slug, Incilaria fuhstorferi. J Comp Physiol [A] 174:111-120.

Kawahara S, Yano M, Shimizu H (1995) Modulation of the feeding system by a radular mechanosensory neuron in the terrestrial slug, Incilaria fuhstorferi. J Comp Physiol [A] 176:193-203.

Klein AN, Weiss KR, Cropper EC (1998) Glutamate is the fast excitatory neurotransmitter of peptidergic mechanosensory neuron B21. Soc Neurosci Abstr 23:359.

Kupfermann I (1974) Feeding behavior in Aplysia: a simple system for the study of motivation. Behav Biol 10:1-26.

Lloyd PE, Frankfurt M, Stevens P, Kupfermann I, Weiss KR (1987) Biochemical and immunocytological localization of the neuropeptides FMRFamide, $\mathrm{SCP}_{\mathrm{A}}, \mathrm{SCP}_{\mathrm{B}}$, to neurons involved in the regulation of feeding in Aplysia. J Neurosci 7:1123-1132.

Meyrand P, Weimann JM, Marder E (1992) Multiple axonal spike initiation zones in a motor neuron: serotonin activation. J Neurosci 12:2803-2812.

Miller MW, Rosen SC, Schissel SL, Cropper EC, Kupfermann I, Weiss KR (1994) A population of SCP-containing neurons in the buccal ganglion of Aplysia are radula mechanoafferents and receive excitation of central origin. J Neurosci 14:7008-7023.

Morton DW, Chiel HJ (1993a) In vivo buccal nerve activity that distinguishes ingestion from rejection can be used to predict behavioral transitions in Aplysia. J Comp Physiol [A] 172:17-32.

Morton DW, Chiel HJ (1993b) The timing of activity in motor neurons that produce radula movements distinguishes ingestion from rejection in Aplysia. J Comp Physiol [A] 173:519-536.

Mulloney B, Selverston A (1972) Antidromic action potentials fail to demonstrate known interactions between neurons. Science 177:69-72.
Newman EA, Hartline PH (1981) Integration of visual and infrared information in bimodal neurons of the rattlesnake optic tectum. Science 213:789-791.

Pearson KG (1993) Common principles of motor control in vertebrates and invertebrates. Annu Rev Neurosci 16:265-297.

Pearson KG, Ramirez JM (1997) Sensory modulation of patterngenerating circuits. In: Neurons, networks, and motor behavior (Stein PSG, Grillner S, Selverston AI, Stuart DG, eds), pp 225-235. Cambridge, MA: MIT.

Rao G, Barnes CG, McNaughton BL (1986) Intracellular fluorescent staining with carboxyfluorescein: a rapid and reliable method for quantifying dye-coupling in mammalian central nervous system. J Neurosci Methods 16:251-263.

Redman SJ (1998) The relative contributions of $\mathrm{GABA}_{\mathrm{A}}$ and $\mathrm{GABA}_{\mathrm{B}}$ receptors to presynaptic inhibition of group Ia EPSPs. In: Presynaptic inhibition and neural control (Rudomin P, Romo R, Mendell LM, eds), pp 162-177. New York: Oxford UP.

Reingold SC, Gelperin A (1980) Feeding motor programme in Limax. II. Modulation by sensory inputs in intact animals and isolated central nervous systems. J Exp Biol 85:1-19.

Rosen SC, Weiss KR, Kupfermann I (1982) Cross-modality sensory integration in the control of feeding in Aplysia. Behav Neural Biol 35:56-63.

Rosen SC, Teyke T, Miller MW, Weiss KR, Kupfermann I (1991) Identification and characterization of cerebral-to-buccal interneurons implicated in the control of motor programs associated with feeding in Aplysia. J Neurosci 11:3630-3655.

Rosen SC, Weiss KR, Kupfermann I (1997) Functional specificity of a command-like interneuron in the feeding system of Aplysia. Soc Neurosci Abstr 23:1045.

Rosen SC, Miller MW, Cropper EC, Kupfermann I (2000a) Phasedependent modulation of the activity of an identified mechanoafferent neuron (B21) is produced by the actions of sensory neurons, motor neurons and interneurons comprising the feeding pattern generator network in Aplysia. J Neurophysiol, in press.

Rosen SC, Miller MW, Evans CG, Cropper EC, Kupfermann I (2000b) Diverse synaptic connections mediate interactions between identified peptidergic radula mechanoafferent neurons and pattern generator cells in the feeding system of Aplysia. J Neurophysiol, in press.

Rossignol S, Beloozerova I, Gossard JP, Dubuc R (1998) Presynaptic mechanisms during locomotion. In: Presynaptic inhibition and neural control (Rudomin P, Romo R, Mendell LM, eds), pp 385-397. New York: Oxford UP.

Shapiro E, Castellucci V, Kandel ER (1980) Presynaptic membrane potential affects transmitter release in an identified neuron in Aplysia by modulating the $\mathrm{Ca} 2+$ and $\mathrm{K}+$ currents. Proc Natl Acad Sci USA 77:629-633.

Siegler MVS (1977) Motor neurone coordination and sensory modulation in the feeding system of the mollusc Pleurobranchaea californica. $\mathrm{J}$ Exp Biol 71:27-48.

Sillar KT (1991) Spinal pattern generation and sensory gating mechanisms. Curr Opin Neurobiol 1:583-589.

Steinberg TH, Newman AS, Swanson JA, Silverstein SC (1987) Macrophages possess probenecid-inhibitable organic anion transporters that remove fluorescent dyes from the cytoplasmic matrix. J Cell Biol 105:2695-2702.

Susswein AJ, Rosen SC, Gapon S, Kupfermann I (1996) Characterization of buccal motor programs elicited by a cholinergic agonist applied to the cerebral ganglion of Aplysia californica. J Comp Physiol [A] 179:509-524.

Wallace MT, Meredith MA, Stein BE (1998) Multisensory integration in the superior colliculus of the alert cat. J Neurophysiol 80:1006-1010.

Weiss KR, Chiel HJ, Koch U, Kupfermann I (1986) Activity of an identified histaminergic neuron, and its possible role in arousal of feeding behavior in semi-intact Aplysia. J Neurosci 6:2403-2415.

Wolf H, Burrows M (1995) Proprioceptive sensory neurons of a locust leg receive rhythmic presynaptic inhibition during walking. J Neurosci 15:5623-5636. 